\title{
Performance Evaluation of DFIG During Asymmetrical Grid Disturbances Using Internal Model Controller and Resonant Controller
}

\author{
D.V.N. Ananth ${ }^{1}$ and G.V. Nagesh Kumar ${ }^{2}$ \\ ${ }^{1}$ Dept. of Electrical \& Electronics Engineering, DADI Institute of Engineering \& Technology \\ (DIET), Anakapalli, Visakhapatnam, India \\ ${ }^{2}$ Dept. of Electrical \& Electronics Engineering, GITAM University, Visakhapatnam, India \\ nagaananth@ieee.org, drnagesh@gitam.edu
}

\begin{abstract}
In this paper, grid disturbances like asymmetrical sag and swell faults in phase-A are analyzed for the grid connected DFIG. The dynamic behavior of DFIG is compared and tabulated with results using state error compensators like PI, PI with resonant (PIR) and internal model control (IMC) on rotor side converter (RSC). The RSC is designed analytically with enhanced field oriented control (EFOC) technique for better performance during such grid disturbances. In this technique, rotor flux reference changes from synchronous speed to some smaller speed or zero during the fault for injecting current at the rotor slip frequency. In this process, DC-Offset component of flux is controlled in not decomposing into a lower value of faults and maintaining it. This offset decomposition of flux will be oscillatory in conventional FOC, whereas in EFOC with internal model controller, flux can damp quickly not only for single fault but multiple faults. This strategy can regulate stator and rotor current waveform to sinusoidal without much distortion during and after fault. It has better damped torque oscillations, control in rotor speed and generator flux during and after fault. The fluctuations in DC bus voltage across capacitor are also controlled using proposed EFOC technique. The system performance with phase-A over voltage and under-voltage with above controllers and EFOC technique are analyzed using simulation studies.
\end{abstract}

Keywords: Asymmetrical grid disturbance; DFIG; Field oriented control; Internal model control (IMC); PI and resonant controoller (PIR); unbalanced and distorted load.

\section{INTRODUCTION}

In the comparison between other wind turbines driven generators, the doubly fed induction generator (DFIG) is having more advantages. The major reasons like better real and reactive power capability, variable speed constant frequency operation etc. make it to stand at the top of all. However, it is sensitive to asymmetrical grid disturbances like single phase or two phase's voltage disturbances as it are directly connected to grid. Based on modern grid rules, DFIG needs to operate effectively on asymmetrical faults and also under unbalanced and distorted loading conditions.

The status of research on the LVRT issue for DFIG for symmetrical and asymmetrical faults and comparison of different control strategies is given in [1]. Understanding the capability of RSC to deliver desired reactive power and withstanding capability during fault in [2]. LVRT enhancement based on flux trajectory [3], effect of different types of faults were studied in [4] for DFIG. Controlling DC link current of RSC to smoothen DC voltage fluctuations due to grid faults by using stored Kinetic Energy [5] is proposed in this paper. RSC with static damping resistor placed in series with stator windings to limit torque oscillations and transient response is done in [6]. FFTC scheme with PIR [7] and PI [8] are adopted for symmetrical and asymmetrical faults for improving uninterrupted P, Q supply from wind turbine (WT) to grid. Few control phase sequence control techniques [9-12] were adopted for improving the performance during unbalanced LVRT. Reference current based rotor and grid side converter (RSC and GSC) control schemes for performance improvement during unbalanced faults [13]

Received: October $14^{\text {th }}, 2015$. Accepted: August $23^{\text {rd }}, 2016$

DOI: 10.15676/ijeei.2016.8.3.3 
are analyzed. In the methods like phase sequence technique, control techniques are very complicated and can improve generator voltage and current profiles to certain extent only. Also, DC voltage fluctuations across capacitor will be high during grid asymmetrical disturbances. However controller like PI and resonant (PIR) will help in improving the system performance effectively based on the effectiveness of control strategy used.

In general due to asymmetrical grid faults, there will be large Electromagnetic Torque (EMT) oscillations, stator terminal in that particular phase voltage to decrease, DC link voltage across capacitor to fluctuate and speed of rotor varies during fault. The basic objective of this paper is to minimize all these affects and further to improve the voltage and current profile of stator and rotor during faults. During phase-A dip or rise in grid voltage, stator EMF decreases with decrease in the flux value. The EMT oscillations occur to single or two phases dip and reach to very low or zero value. Also, when a fault occurs, due to slower response mechanical energy remains almost constant compared to decrease in electrical energy output. This difference in energy conversion makes rotor shaft to rotate quicker and tends the system towards instability. If decay in rotor flux is controlled, stability can be regained. This can be achieved by controlling the offset component of stator flux by changing its synchronous speed reference to a new reference value. Also control in DC link voltage across capacitor also plays a vital role. Hence EFOC technique is developed to control decay in rotor flux, varying synchronous speed of stator, better reactive power control to limit the deviation in electro-mechanical conversion during faults. Within the scope of its power limits, for any type of sag or swell asymmetrical and symmetrical disturbances, DFIG with EFOC helps in improving reliability and lifetime of overall system. The efficacy of system with sag and swell faults will be analyzed in the next section.

The system performance is studied with $30 \%$ increase from grid voltage during 0.6 to $0.75 \mathrm{~s}$ and voltage dip of $50 \%$ between 1.15 and $1.4 \mathrm{~s}$ in phase-A. Remaining time the system is working under normal conditions. The voltage, current and flux parameters at rotor, stator windings, grid voltage and DFIG electromagnetic torque, speed of the rotor was compared and analyzed. For this proposed enhanced field oriented control (EFOC) technique performance is compared with PI and PI with resonant (PIR) and internal model controller (IMC).

There are studies to minimize the rotor fault current by incorporating specific control scheme in RSC [2-8]. These techniques are designed to limit the fault current entering to rotor windings and damaging the converters, the crowbar is widely used. However, it requires additional hardware and it cannot completely make the system free from fault. So, recently few papers proposed a control scheme that does not require a crowbar [18]. Few papers used fault current limiters SMES etc. to limit surge currents [17-20]. These methods are also cost effective with sophisticated techniques. The LVRT with external devices like fault current limiter are used to suppress surge currents produced in the rotor during severe faults [22-24]. In the above control schemes, the torque is fixed to zero and the reactive power must be drawn from the grid. This makes the DFIGURE system to more prone to the fault and weakens the system. The demagnetization control technique is widely used to suppress the natural stator flux components which help in damp flux oscillations. However, from literature it is found that demagnetization technique is sensitive to variation in the system parameter as stator resistance knowledge is required. The above sensitivity can be reduced by combining with virtual resistance methodology or arbitrary change in the RSC phase locked loop reference in changing the arbitrary value of speed of stator and rotor reference. The above effects are reduced by changing mostly the inner current control loop with surge current limiters and fast acting control strategy. Hence for this, our EFOC technique is adopted with fast changing inner control loop with arbitrary changing speed reference with surge current limiter technique. The flux decomposition is also controlled with our proposed control scheme. To improve the fault ride through for DFIG during symmetrical or asymmetrical faults, new control strategies are proposed and implemented in RSC [25-28]. Feed forward compensation with current reversely tracking control (CRTC) is done in [25], double loop control strategy using proportional and resonant controller is given in [26] and virtual flux damping with tuned PIR in [27 and 28]. 
This paper is an improved demagnetization approach to suppress stator and rotor flux oscillations. For this a new arbitrary reference frame is chosen in the inner RSC control scheme for controlling fault current entering into the system. The flux referees for stator and rotor are derived by using input terminal voltage and current parameters instead of taking from machine parameters. This makes the control action faster and accurate. This technique helps in overcoming the effect of rating of converters for DFIG. The main objective is suppressing the exponentially increasing DC offset component (DCOC) of current during faults, thereby controlling the back emf of DFIG. In general, PI controller is slower in action, so for faster action and better damping of oscillations, IMC is used.

The EFOC technique is designed for improving dynamic and transient stability margin during and after faults. In EFOC technique, rotor flux reference changes its value from synchronous speed to zero or to a smaller value during fault for injecting current at the rotor slip frequency. In this method, DC-offset component of stator flux is controlled to minimize it. This offset decomposition of flux will be oscillatory in a conventional FOC, whereas in EFOC it can damp quickly. The reference frame for rotor during fault changes with EFOC, so as to make the rotor speed not to deviate much from the reference value. This makes the decomposition of flux during fault to be controlled and make the generator winding current not to exceed to higher values. This technique was adopted in the inner control loop of RSC. The authors justified their work by improving modification in RSC, controlling flux or current in rotor winding. A fast acting and accurate controllers like proportional + resonant or PI+ Resonant (PIR) are used to improve the DFIGURE performance during and after the faults with better stability margin. Hence, RSC controller with a controller better than PIR is motivated to adopt in this paper with EFOC technique and IMC.

In the section 2 gives explanation deign of converters for EFOC. In section number 3, mathematical modeling on wind turbine and generator converters for the grid connected DFIG was explained during transient state. In this section, effect of system during symmetrical fault, EFOC control technique and behavior of mechanical and electrical system with variation in rotor speed is explained in sub-sections. In section 4, proposed IMC and PIR are described. Further sections 5 describes the simulation results of phase-A voltage swell to $30 \%$ and sag of $50 \%$ of the rated voltage with PI, PIR and IMC are compared using simulation environment. The discussion on result analysis with tabulated results is given in section 6 , conclusions in section 7. Later appendix and references follows.

\section{Design of Rotor Side Converter Control for EFOC}

RSC controller helps in improving reactive power demand of the grid and to extract maximum power from the machine by making the rotor to run at optimal speed. The optimal speed of the rotor is decided on machine real power and rotor speed characteristic curves from MPPT algorithm. The stator active and reactive power control is possible with the RSC controller strategy through $\mathrm{i}_{\mathrm{qr}}$ and $\mathrm{i}_{\mathrm{dr}}$ components controlling respectively. The rotor voltage in a stationary reference frame [6] and further analysis from [14] is given by

$$
V_{r}^{s}=V_{0 r}^{s}+R_{r} i_{r}^{s}+\sigma L_{r} \frac{d i_{r}^{s}}{d t}-j \omega i_{r}^{s}
$$

with $\sigma=1-\frac{L_{S m}^{2}}{L_{S} L_{r}}$ and

$\omega$ is the rotor speed, $\mathrm{i}_{\mathrm{r}}^{\mathrm{s}}$ is the rotor current in a stationary frame of reference, $\mathrm{L}_{\mathrm{s}}, \mathrm{L}_{\mathrm{r}}$ and $\mathrm{L}_{\mathrm{m}}$ are stator, the rotor and mutual inductance parameters in Henry or in pu.

$$
V_{0 r}^{s}=\frac{L_{m}}{L_{s}}\left(\frac{d}{d t}-j \omega_{s}\right) \Phi_{s}^{s}
$$


It is the voltage induced in the stator flux. Using basic equations, we can get rotor $\mathrm{d}$ and $\mathrm{q}$ axis voltages as

$$
\begin{aligned}
& V_{d r}=\left(R_{r}+\frac{d L_{r}^{\prime}}{d t}\right) i_{d r}-s \omega_{s} L_{r}^{\prime} i_{q r}+\frac{L_{m}}{L_{s}} V_{d s} \\
& V_{q r}=\left(R_{r}+\frac{d L_{r}^{\prime}}{d t}\right) i_{q r}+s \omega_{s} L_{r}^{\prime} i_{d r}+\frac{L_{m}}{L_{s}}\left(V_{q s}-\omega \Phi_{d s}\right)
\end{aligned}
$$

where $\omega$ is rotor speed, $\omega_{\Phi s}$ is speed of stator flux, $\omega_{s}$ is synchronous speed.

The above equations 2 and 3 can be rewritten in terms of decoupled parameters and are designed for RSC controller as in equations 4 and 5.

$$
\begin{aligned}
& \sigma \mathrm{V}_{\mathrm{dr}}=\sigma \mathrm{L}_{\mathrm{r}} \frac{\mathrm{dI}_{\mathrm{dr}}}{\mathrm{dt}}-\omega_{\mathrm{s}} \Phi_{\mathrm{qr}}+\frac{\mathrm{L}_{\mathrm{m}}}{\mathrm{L}_{\mathrm{s}}}\left(\mathrm{V}_{\mathrm{ds}}-\mathrm{R}_{\mathrm{s}} \mathrm{I}_{\mathrm{ds}}+\omega_{1} \Phi_{\mathrm{qs}}\right) \\
& \sigma \mathrm{V}_{\mathrm{qr}}=\sigma \mathrm{L}_{\mathrm{r}} \frac{\mathrm{dI} \mathrm{Ir}_{\mathrm{qr}}}{\mathrm{dt}}+\omega_{\mathrm{s}} \Phi_{\mathrm{dr}}-\frac{\mathrm{L}_{\mathrm{m}}}{\mathrm{L}_{\mathrm{s}}}\left(\mathrm{R}_{\mathrm{s}} \mathrm{I}_{\mathrm{qs}}+\omega_{1} \Phi_{\mathrm{ds}}\right)
\end{aligned}
$$

In general the rotor speed $\omega_{\mathrm{r}}$ is and the synchronous speed of stator is $\omega_{\mathrm{s}}$. But this synchronous frequency has to be changed from $\omega_{\mathrm{s}}$ to a new synchronous speed value as described in flowchart $\omega_{\mathrm{s}}^{\prime}[14]$ as it is represented commonly by $\omega_{1}$. Under ideal conditions, reference stator d-axis flux $\Phi_{\mathrm{d}}^{*}$ is zero and q-axis flux $\Phi_{\mathrm{q}}^{*}$ is equal to the magnitude of stator flux $\Phi_{\mathrm{s}}$ for given back emf and rotor speed. The transient rotor $\mathrm{d}-\mathrm{q}$ current is given by equations (6A and $6 \mathrm{~B}$ ) as

$$
\begin{aligned}
& \frac{d i_{d r}}{d t}=\frac{-R_{r}}{\sigma L_{r}} i_{d r}+s \omega_{s} i_{q r}+\frac{1}{\sigma L_{r}} V_{d r} \\
& \frac{d i_{q r}}{d t}=\frac{-1}{\sigma}\left(\frac{R_{r}}{L_{r}}+\frac{R_{s} L_{m}^{2}}{L_{S}^{2} L_{r}}\right) i_{q r}+s \omega_{s} i_{d r}+\frac{1}{\sigma L_{r}} V_{q r}
\end{aligned}
$$

The reference rotor voltages in d-q transformation can be rewritten from equations 4 and 5 and from the control circuit are given below. This is the output voltage from rotor windings during normal and transient conditions.

$$
\begin{aligned}
& \mathrm{V}_{\mathrm{qr}}^{*}=\left(\mathrm{i}_{\mathrm{dr}}^{*}+\frac{1}{\sigma}\left(\frac{\mathrm{R}_{\mathrm{r}}}{\mathrm{L}_{\mathrm{r}}}+\frac{\mathrm{R}_{\mathrm{s}} \mathrm{L}_{\mathrm{m}}^{2}}{\mathrm{~L}_{\mathrm{s}}^{2} \mathrm{~L}_{\mathrm{r}}}\right) \mathrm{i}_{\mathrm{qr}}+\mathrm{s} \omega_{\mathrm{s}} \mathrm{i}_{\mathrm{dr}}\right) \sigma \mathrm{L}_{\mathrm{r}} \\
& \mathrm{V}_{\mathrm{qr}}^{*}=\left(\mathrm{i}_{\mathrm{dr}}^{*}+\frac{1}{\sigma}\left(\frac{\mathrm{R}_{\mathrm{r}}}{\mathrm{L}_{\mathrm{r}}}+\frac{\mathrm{R}_{\mathrm{s}} \mathrm{L}_{\mathrm{m}}^{2}}{\mathrm{~L}_{\mathrm{s}}^{2} \mathrm{~L}_{\mathrm{r}}}\right) \mathrm{i}_{\mathrm{qr}}+s \omega_{\mathrm{s}} \mathrm{i}_{\mathrm{dr}}\right) \sigma \mathrm{L}_{\mathrm{r}}
\end{aligned}
$$

The overall block diagram of RSC is presented in Figure. 1a and GSC is shown in Figure. $1 \mathrm{~b}$. The rotor speed is multiplied with pole numbers and is subtracted from angular grid synchronous frequency. Later integrated and given a $90^{\circ}$ phase shift to get the rotor slip injection frequency angles $\left(\theta_{\mathrm{s}}\right)$. The flux derivation technique helps in understanding the operation of DFIG during steady state and transient state. The accuracy of system performance during steady state depends on accuracy of wind speed measurement action of pitch angle controller, measurement of stator current, voltage, flux and other parameters. The more accurate these measurements, the more can be real power extracted from DFIG wind turbine system. The equation 4 to 7 plays a vital role in understanding the behavior of DFIG during steady state and transients. The accuracy of RSC depends on control of $d$ and $q$ axis voltages. 


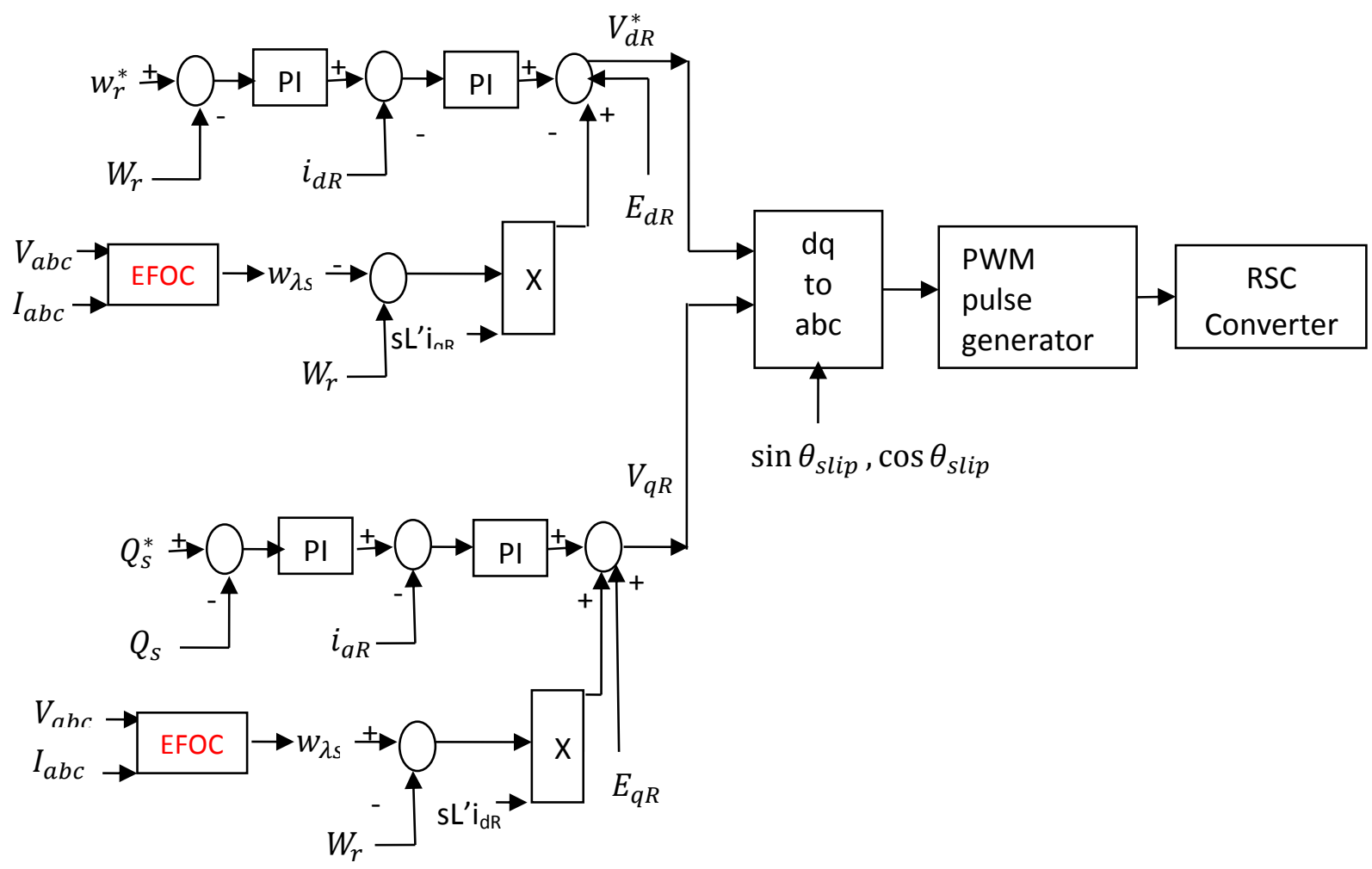

Figure 1a. Complete RSC controller design

The equations 4 to $7 \mathrm{~b}$ describe the design procedure for RSC and the necessity to control the rotor and voltage parameters. The equations 8 to $15 \mathrm{~b}$ are helpful in understanding the behaviour of DFIG during and after the faults. The equation 8 decribes the flux change during suddent transient and its exponential decay. The interaction between stator and rotor flux during the fault and control in the decay in stator flux understanding are important for effective operation during fauts. The equations from 9 to $15 \mathrm{~b}$ are back emf component in the rotor during normal and transient conditions. The equations 
D.V.N. Ananth, et al.

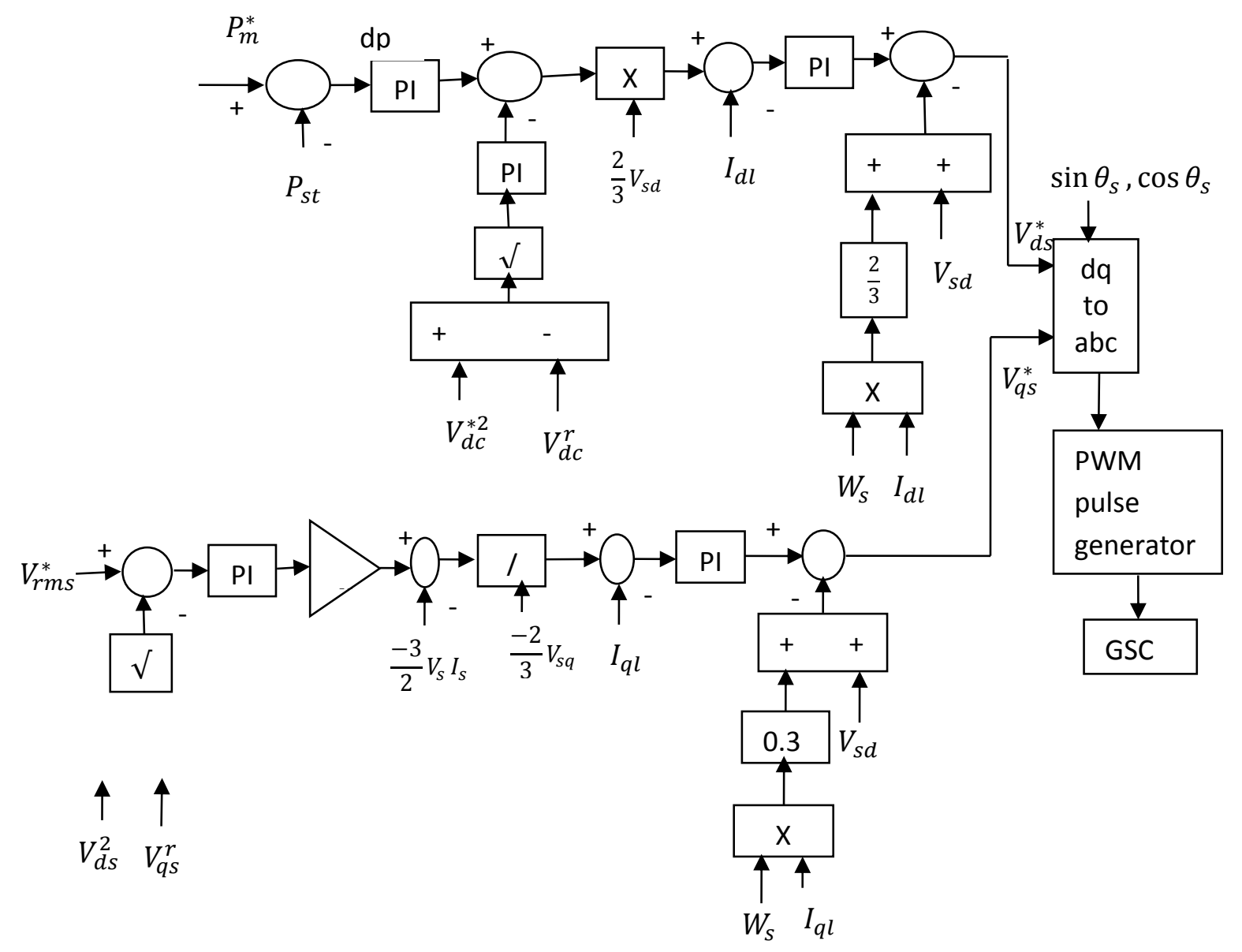

Figure 1b. Grid side controller for DFIG 
14 to $15 \mathrm{~b}$ describes how the stator flux changes during the fault. To control the flux interaction between stator and rotor, rotor reference flux need to be changed. This can be achieved by controlling more effectively the decay of flux during a fault. For this, rotor speed has to be changed as described by equations $15 \mathrm{a}$ and $15 \mathrm{~b}$ to make the rotor to rotate at different speed other than at slip speed described by $\omega_{\mathrm{f}}$. This technique is adopted in RSC as shown in Figure 1a with internal control circuit for EFOC in figure.2.

The dc voltage maintenance across the capacitor is also very important during the fault. Also, GSC need to supply reactive power like a shunt compensator to improve voltage profile after the fault instant. Hence the robust GSC controller strategy needs to be adopted. The future scope can be, decrease in surges and maintenance of constant stator and rotor current value during any disturbance. With the proposed control strategy, smooth transition in electromagnetic torque is achieved during symmetrical fault based transient state of drop in grid voltage and restoring is possible. The dynamic stability of DFIG was improved and thereby mitigation of generator stator and rotor voltages and current are superior with EFOC fuzzy technique. The output power from the generator is better damping the transient stator flux. This is possible by changing the reference flux reference value by choosing particular stator flux $\left(\lambda_{\mathrm{s}}\right)$ value. Otherwise over current in the rotor winding makes the system performance and lifetime to degrade under these situations.

\section{Mathematical Analysis of RSC and GSC Converters for The Grid Connected DFIG During Transient State}

\section{A. Three Phase Symmetrical or asymmetrical Faults}

The stator voltage will reach to zero magnitude during severe three phase's symmetrical fault of low impedance and stator flux $\Phi_{s}$ gets reduced to zero magnitude. The decay in stator and rotor flux is not as rapid as in voltage and can be explained using flux decay theorem. This delay in flux is because of inertia time lagging $\tau_{s}=\frac{L_{s}}{R_{s}}$. This parameter affect the rotor induced $\mathrm{emfV}_{0 \mathrm{r}}$. The flux during fault is given by

$$
\Phi_{\text {sf }}^{\mathrm{s}}=\Phi_{\mathrm{s}}^{\mathrm{s}} \mathrm{e}^{-\mathrm{t} / \tau_{\mathrm{s}}}
$$

and $\frac{d \Phi_{\text {sf }}^{\mathrm{S}}}{\mathrm{dt}}$ is negative, indicating its decay. By substituting (8) in (1b)

$$
V_{0 r}^{s}=-\frac{L_{m}}{L_{s}}\left(\frac{1}{\tau_{s}}+j \omega\right) \Phi_{s}^{s} e^{-t / \tau_{s}}
$$

The above equation is converted into a rotor reference frame and neglecting $\frac{1}{\tau_{s}}$

$$
V_{0 r}^{s}=-\frac{L_{m}}{L_{s}}(j \omega) \Phi_{s}^{s} e^{-j \omega t}
$$

By substituting $\Phi_{s}^{s}=\frac{V_{s}^{s}}{j \omega_{s}} e^{-j \omega_{s} t}$ in (10)

$$
V_{0 r}^{r}=-\frac{L_{m}}{L_{s}}(1-s) V_{s}
$$

$\left|\mathrm{V}_{0 \mathrm{r}}^{\mathrm{r}}\right|$ is proportional to (1-s)

The converting equation (1a) into the rotor reference frame

$$
V_{r}^{r}=V_{0 r}^{r} e^{-j \omega t}+R_{r} i_{r}^{r}+\sigma L_{r} \frac{d i_{r}^{r}}{d t}
$$


The rotor voltage during fault is given by

$$
\begin{aligned}
& V_{r}=i_{r} R_{r}+\sigma L_{r} \frac{d i_{r}}{d t}+V_{o r} \\
& \text { or } \\
& V_{r}=i_{r} R_{r}+\sigma L_{r} \frac{d i_{r}}{d t}+\frac{L_{m}}{L_{s}} \frac{d \phi_{s}}{d t}
\end{aligned}
$$

In the above equation (13B), the first two terms on RHS determine the voltage drop by rotor current due to passive elements and the last term determines the EMF induced by the stator flux [14].

During the fault, at first instant, $\Phi_{\mathrm{s}}$ does not fall instantly described by equation (8). If the machine is running at super synchronous speed with slip (s) around $-0.2 \mathrm{pu}$, during the fault, rotor speed increases. It is based on the term (1-s) as in equation (11). The above speed change is uncontrollable for a generator having higher electrical and mechanical inertia constants. In order to control the rotor current change, $V_{r}^{r}$ has to be increased based on equation (12). Based on the first reason, the voltage $V_{\Phi s}$ will be injected in the feed forward path to improve the rotor dip to reach to its near steady state value. Converting equation (10) to synchronous reference frame and considering direct alignment of $\Phi_{\mathrm{ds}}$ with $\Phi_{\mathrm{s}}$ we get,

$$
\mathrm{V}_{\Phi \mathrm{s}}=-\frac{\mathrm{L}_{\mathrm{m}}}{\mathrm{L}_{\mathrm{s}}} \omega \Phi_{\mathrm{ds}}
$$

The second technique for voltage increase requirement in a rotor is: dip can be compensated when replacing $s \omega_{s}$ with $\left(\omega_{\Phi s}-\omega\right)$ in cross coupling terms with $s \omega_{s} L_{r}^{\prime} i_{q r}$ and $s \omega_{s} L_{r}^{\prime} i_{d r}$ respectively. The reduction in magnitude and frequency of flux $\Phi_{s}$, and alignment of flux with the stator voltage without the rate of change in flux angle $\theta_{\Phi s}$ indicates DC offset component in flux.

$$
\frac{\mathrm{d} \phi_{\mathrm{s}}}{\mathrm{dt}}=\omega_{\phi s}=0=\omega_{\mathrm{f}}
$$

Here, $\omega_{\mathrm{f}}$ is the speed of stator flux during fault and this value can be made to zero as offset. The compensation for DFIG during depends on RSC rating. If further decrease in grid voltage, external active devices like energy storage devices or FACTS devices are helpful.

The same control strategy for a single phase to the ground as well as two phases to ground faults can be applied. However due to the presence of positive and negative sequence components, the rate of change in flux angle $\theta_{\phi s}$ and magnitude change in flux is observed [4], given by

$$
\frac{\mathrm{d} \theta_{\phi s}}{\mathrm{dt}}=\omega_{\phi s}=\frac{\mathrm{v}_{\beta s} \phi_{\alpha s}-\mathrm{v}_{\alpha s} \phi_{\beta s}}{\phi_{\alpha \mathrm{s}}^{2}+\phi_{\beta s}^{2}}=\omega_{\mathrm{f}}
$$

When dynamic stability has to be improved, proposed technique controls the decrease in stator and rotor flux magnitude and also damps oscillations at the fault instances. To achieve better performance during transients, this paper proposes a strategy for stator frequency reference to change from zero or other values depending type and severity of disturbance. The accurate measurement of stator and rotor parameters like flux, current helps in achieving better performance during transients. The DC offset stator current reduction in transients and making the two axis flux and voltage trajectories circulars also improves the efficacy of the system performance during any faults. The equations 8 to 15 helps in understanding DFIG behavior during transient conditions and accuracy of its working depends on measurement of rotor current and flux parameters. 
B. Behavior of mechanical and electrical system with the variation in rotor sped and reactive power

The mechanical to electrical relationship is explained as follows. The rotor speed can be expressed as

$$
\omega_{\mathrm{r}}=(1-\mathrm{s}) \omega_{\mathrm{s}}=\mathrm{p} \eta \omega_{\omega \mathrm{t}}
$$

Where $s$ is slip of DFIG, $p$ is pair of poles of DFIG; $\eta$ is gearbox ratio and $\omega_{\omega t}$ is wind turbine speed. With the change in wind speed and depending on gears ratio and number of field poles, the rotor speed varies is shown in equation 33. When rotor speed varies, reference quadrature axis current changes, thereby current flow in the rotor circuit varies. The stator output also varies from variation in wind turbine speed and DFIG output power. When slip to vary, the voltage in rotor circuit also varies which can be explained as per equations 8 and 9 .

The mechanical turbine tip speed ratio (TSR) can be written in terms of the radius of turbine wings $(\mathrm{R})$, angular stator speed $\left(\omega_{\mathrm{s}}\right)$, pole pairs and gear box ratio as

$$
\lambda=\frac{\mathrm{R} \omega_{\mathrm{s}}}{\mathrm{p} \eta \mathrm{v}_{\mathrm{w}}}(1-\mathrm{s})
$$

Increase in stator or grid frequency, TSR increases and vice versa. Similarly with increase in rotor speed or wind speed, TSR decreases and vice versa. Hence when an electrical system gets disturbed, mechanical system also will get some turbulence and electrical to mechanical system is tightly interlinked. The steady state behavior of overall system must satisfy the relation in equation (19).

$$
\Delta \mathrm{P}=\frac{-\mathrm{P}_{\omega \mathrm{t}}}{(1-\mathrm{s})}-\mathrm{P}_{\mathrm{em}}=0
$$

Under normal conditions, the change in turbine output has to be compensated by electrical power output from DFIG. Otherwise slip gets changed and thereby rotor speed changes. Hence imbalance in mechanical to electrical power output ratios, the slip changes. With the change in coefficient of power $\mathrm{Cp}$, the mechanical power varies. The mechanical power changes mostly when wind speed or air density of the turbine wings changes. The electrical power from DFIG changes when mechanical power changes or rotor speed changes or load demand from grid varies.

A considerable decrease in pre-fault steady state voltage $V_{0 r}^{r}$ to certain fault voltage during a three phase fault was explained in above analytics. However, RSC converter is designed to meet $V_{r}^{r}$ to match $V_{0 r}^{r}$ for rotor current control and the design has to be made for rating of only $35 \%$ of stator rated voltage. The voltage dip during the fault can be adopted independently or in coordination by using two techniques is explained below.

During the fault, at first instant, $\Phi_{\mathrm{s}}$ does not fall instantly based on equations ( 9 or 15 ). If the machine is running at super synchronous speed with slip (s) near to $-0.2 \mathrm{pu}$, during fault, rotor speed further increases based on the term (1-s) as given by (9). The above speed change is uncontrollable for a generator having higher electrical and mechanical inertia constants. In order to control the rotor current change, $\mathrm{V}_{\mathrm{r}}^{\mathrm{r}}$ has to be increased. Based on the first reason listed above, a voltage $V_{\Phi s}$ to be injected in the feed forward path of improving the rotor dips to reach to its near steady state value. The second technique for voltage increase requirement in a rotor is, dip can be compensated by replacing $s \omega_{s}$ with $\left(\omega_{\Phi s}-\omega\right)$ in cross coupling terms $s \omega_{s} L_{r}^{\prime} i_{q r}$ and $s \omega_{s} L_{r}^{\prime} i_{d r}$ respectively. The reduction in magnitude and frequency of flux $\Phi_{s}$, and alignment of flux with the stator voltage without the rate of change in flux angle $\theta_{\Phi s}$ indicates DC offset component in flux during single line to ground (SLG) fault. 


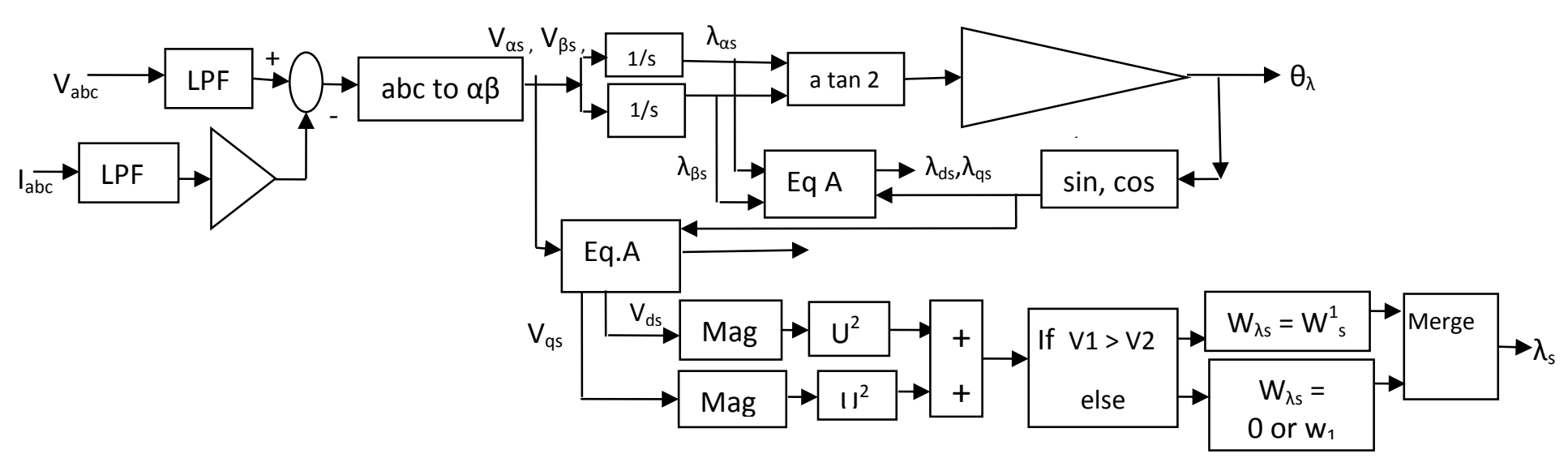

Figure 2. EFOC control loop design with DCOC and rotor flux trajectory control

\section{Design of IMC and PIR for DFIG Based System During Symmetrical Faults}

The block diagram representation of the conventional internal model controller (IMC) for DFIGURE is shown in Figure. 3a. The mathematical modeling of IMC is given below

$$
\begin{aligned}
& \omega_{r}=\frac{K_{t}}{J_{m}} i_{q}-\frac{B \omega_{r}}{J_{m}}-\frac{T_{L}}{J_{m}} \\
& \omega_{r}^{*}=\frac{K_{t}}{J_{m}} i_{q}^{*}-\frac{B \omega_{r}}{J_{m}}-\frac{K_{t} d(t)}{J_{m}} \\
& d(t)=\frac{-T_{L}}{K_{t}}-\left(i_{q^{*}}^{*}-i_{q}\right)
\end{aligned}
$$

where $\omega_{\mathrm{r}}$ is the differential rotor speed of DFIG. The speed controller block $\mathrm{C}_{\mathrm{IMC}}(\mathrm{s})$ is written as

$$
\mathrm{C}_{\mathrm{IMC}}(\mathrm{s})=\mathrm{G}(\mathrm{s}) \mathrm{F}(\mathrm{s})
$$


$\mathrm{G}(\mathrm{s})=\frac{1}{\mathrm{~J}^{\prime} \mathrm{s}+\mathrm{B}^{1}}$,

Where $\mathrm{J}^{\prime}$ is $\frac{\mathrm{J}}{\mathrm{K}_{\mathrm{t}}}$ and $\mathrm{B}^{\prime}$ is $\frac{\mathrm{B}}{\mathrm{K}_{\mathrm{t}}}$

Where $\mathrm{G}(\mathrm{s})$ is the internal model block and $\mathrm{F}(\mathrm{s})$ is a filter component given by

$$
\mathrm{F}(\mathrm{s})=\frac{1}{\mathrm{Fs}+1}
$$

where ' $\mathrm{F}$ ' in the denominator is time constant for filter and ' $\mathrm{s}$ ' is Laplace constant.

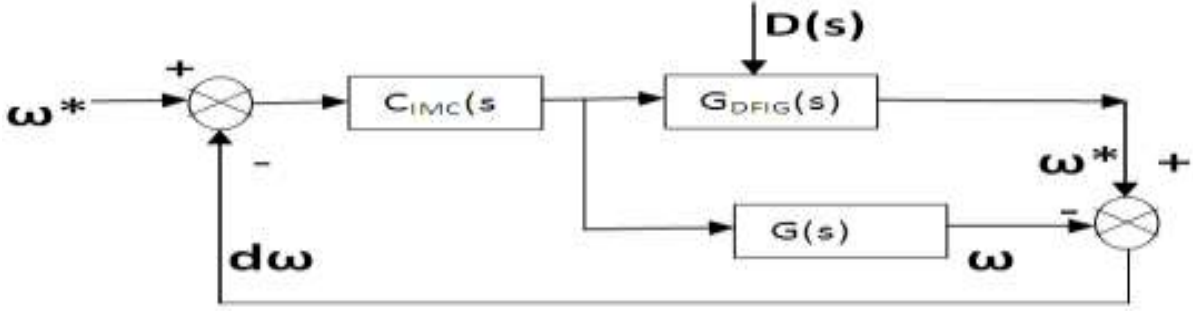

Figure 3a. Conventional IMC technique for DFIGURE

The improved proposed IMC block diagram is shown in figure $3 \mathrm{~b}$ and its implementation in MATLAB is shown in figure $3 \mathrm{c}$.

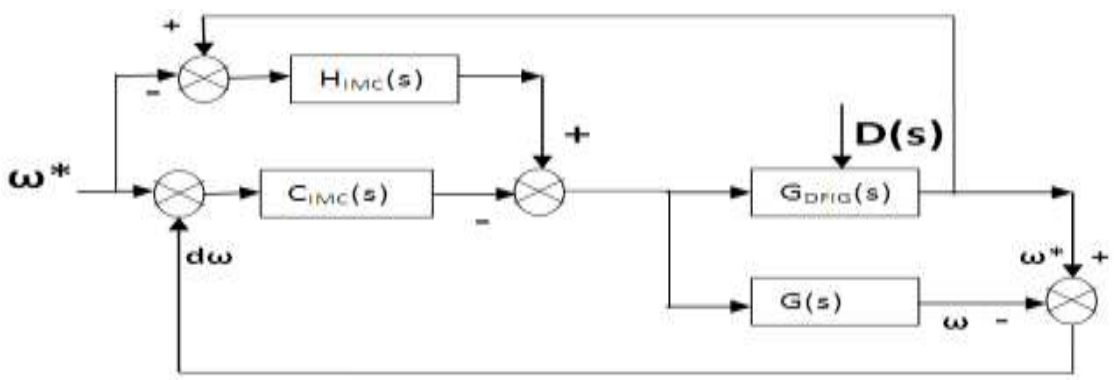

Figure 3b. Improved IMC controller for DFIG

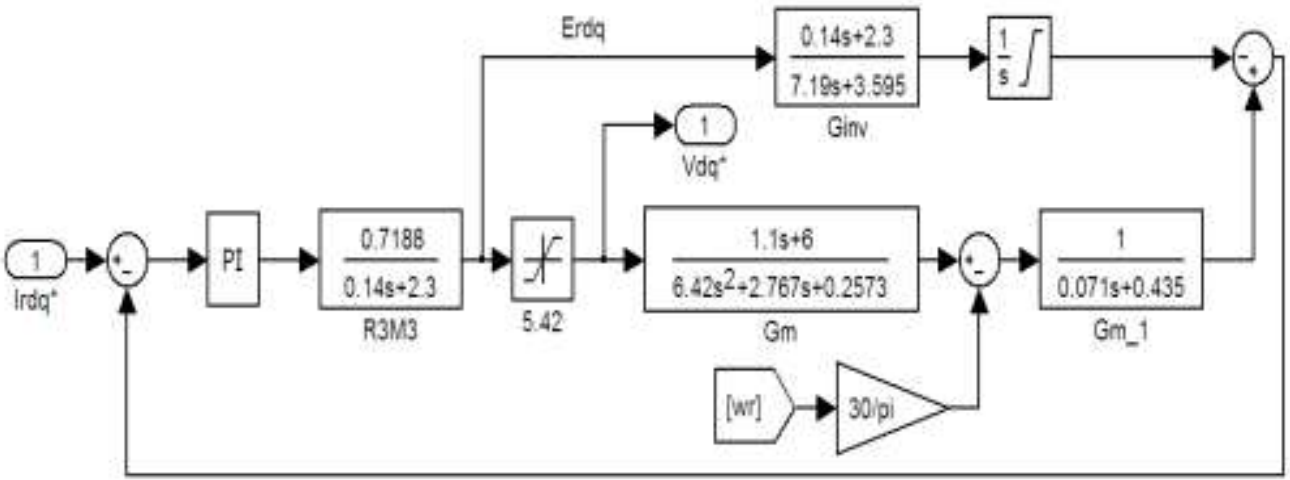

Figure 3c. Implementation of IMC controller for DFIG 


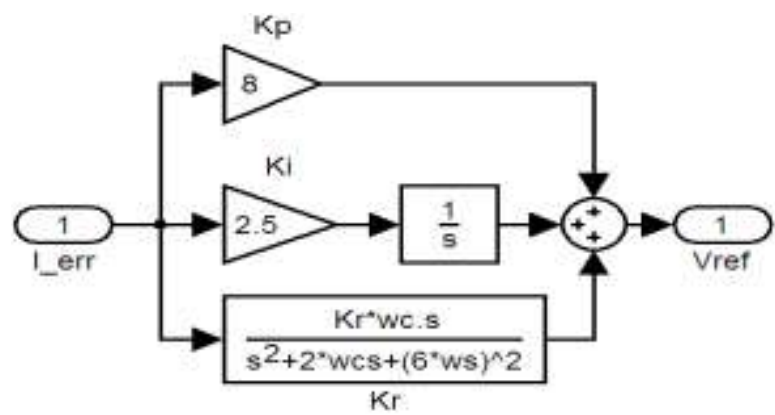

Figure 3d. Implementation of PIR controller for DFIG

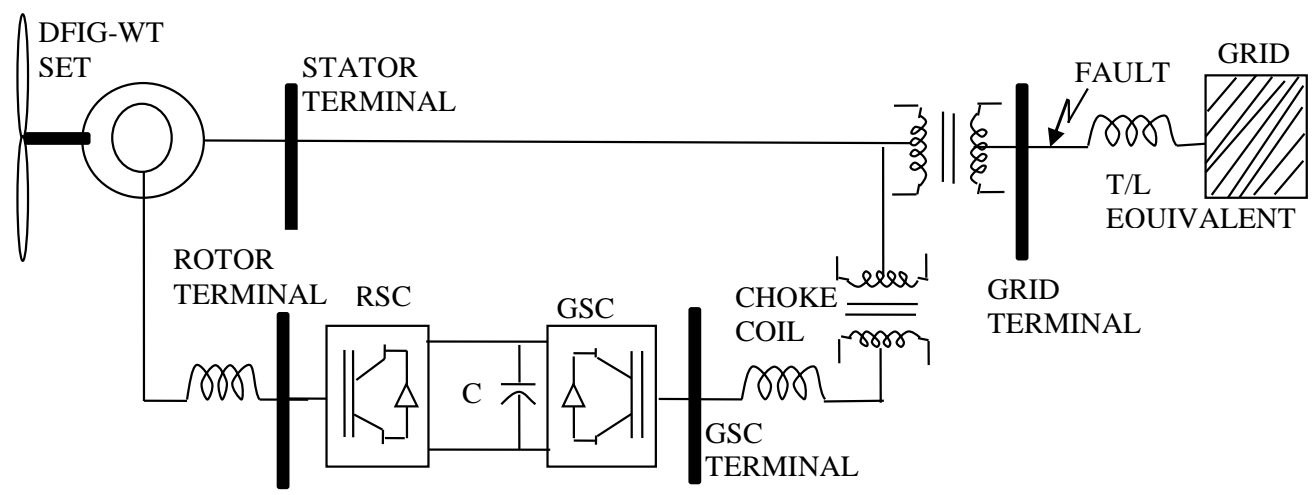

Figure 3e. Configuration of DFIG system connected to grid

The grid connected DFIG is shown in figure. 3e. The real and reactive power from DFIG is controlled by using RSC and GSC controller using converter controller model as shown in Figure.1a and $1 \mathrm{~b}$. The converter model is a bidirectional switches with IGBT (integrated bipolar transistor), which controls the voltage, real and reactive power from stator and rotor to grid. The RSC controller is to maintain DFIG rotor at optimal speed specified by MPPT and also to supply desired reactive power as per grid requirement based on converter and capacitor rating. The GSC controller helps in maintaining constant DC link voltage at the back to back terminals across capacitor. It is for the reason that, that this voltage can be maintained as per PCC and also for rapid supplying with leading or lagging reactive power without much deviation from generator real power. The transformer near the grid is a step-up voltage and the other transformer is an isolation transformer.

With the changes in wind speed, rotor speed will also change by shifting the gears position in the wind turbine. If rotor speed is made to operate on reference wind speed, maximum power can be extracted from wind turbine generator set. This will happen to normal state of operation, but during abnormal conditions like faults, rotor speed increases which may damage gears of wind turbine. Hence speed of DFIG rotor must be controlled. If RSC is designed in a better way, the performance of DFIG can be improved. With deviation from rotor speed, direct axis current of RSC changes and with demand in reactive power during faults or so, quadrature axis component of current changes. When a fault occurs, speed of rotor changes and hence rotor frequency also changes. If with this changed rotor frequency, current is injected into the windings of stator terminal of DFIG, flux decay or oscillations in stator terminal will get reduced. 
The performance of PIR is much better than a conventional PI during disturbance operation. The time taken to reach steady state for a well tuned PI controller is also very high and will have degrading performance during rapid varying disturbance scenarios. Hence PIR is considered for this analysis and the block diagram is shown in Figure.3d. In this $\mathrm{K}_{\mathrm{r}}$ is resonant constant, which provides infinite gain for AC constituents of frequency range of $\pm \omega_{\mathrm{s}}$. The $\omega_{\mathrm{s}}$ and $\omega_{\mathrm{c}}$ is synchronous frequency and cut-off frequency of the system. The $\omega_{\mathrm{c}}$ is inserted into the system to the resonant part to augment its frequency band width [11].

\section{Result Analysis}

The grid voltage and current waveforms for phase-A disturbance in the grid and remaining phases are constant is shown in Figure. 4a. There is a phase A voltage rise of $30 \%$ during 0.6 to 0.75 seconds and sag of $50 \%$ between 1.15 and $1.4 \mathrm{~s}$. Remaining time for 0.75 to $1.15 \mathrm{~s}$, the system is expected to be healthy. The grid phase to ground voltage with EFOC technique with conventional PI and PIR and IM controller are shown in Figure. 4a (i), (ii) and (iii). The phaseA voltage and current increased to $1.3 \mathrm{pu}$ and $0.75 \mathrm{pu}$ during 0.6 to $0.75 \mathrm{~s}$ of swell fault. Under normal conditions between 0.75 to $1.15 \mathrm{~s}$, the grid voltage is $1 \mathrm{pu}$ and current is $0.5 \mathrm{pu}$. During voltage sag in phase A between 1.15 to $1.4 \mathrm{~s}$, voltage is $0.5 \mathrm{pu}$ and current is $0.25 \mathrm{pu}$ in phase A. Remaining phases voltage and current at grid remained constant Their performance are identical as no controller is used to control grid disturbances. The grid asymmetrical fault behavior and its affects on DFIG performance are studied using EFOC. An enhancement in operation is estimated using internal control technique than with a conventional PI controller. Due to phase-A voltage rose, currents in phase $\mathrm{B}$ and $\mathrm{C}$ will increase. With decrease in phaseA voltage, the same current will increase as shown in this figure.
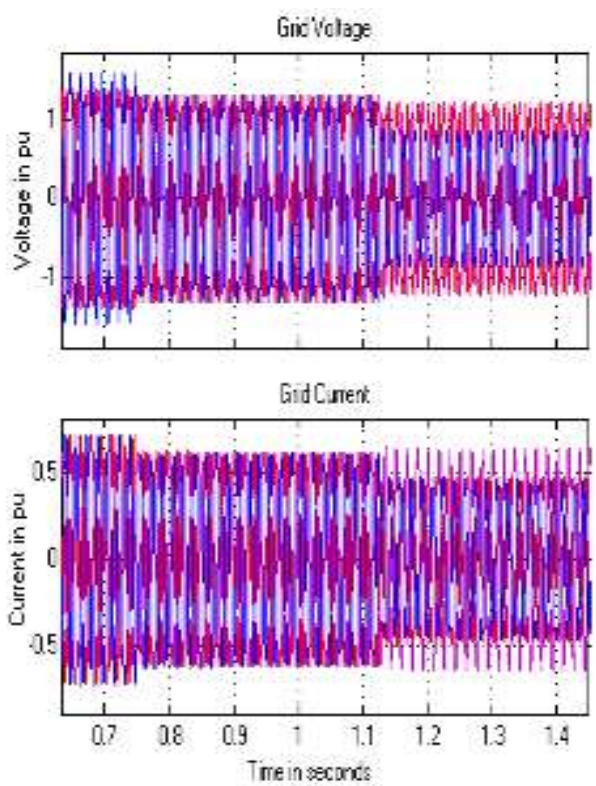

Figure 4a (i) 
D.V.N. Ananth, et al.
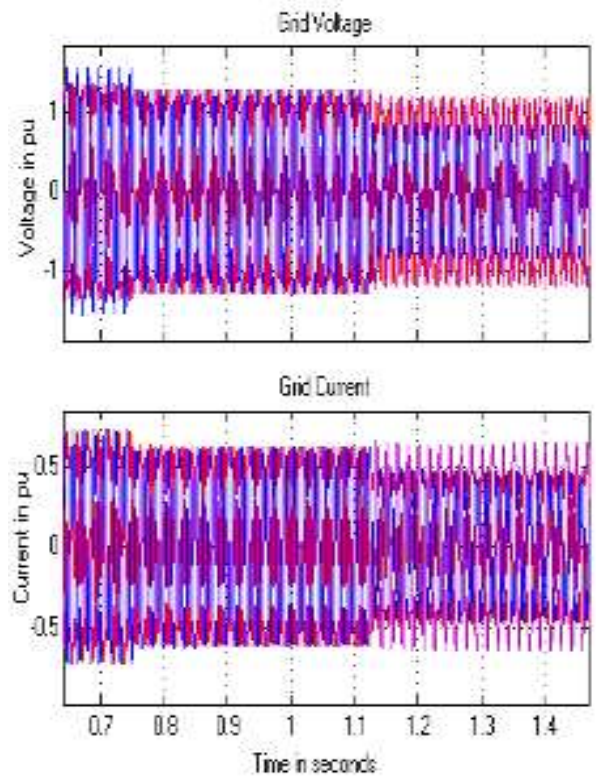

Figure 4a (ii)
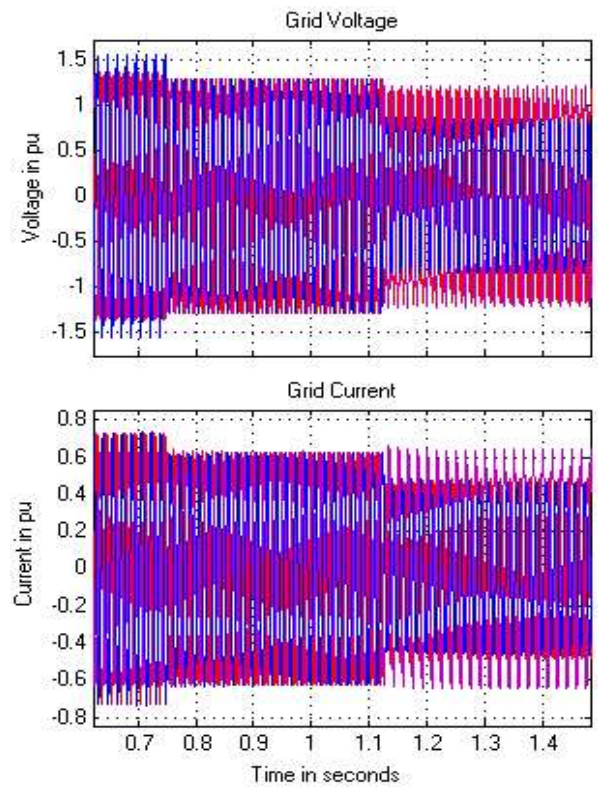

Figure $4 \mathrm{a}$ (iii)

Figure 4a. Grid voltage and current with (i) PI based controller, Figure.4a (ii) PIR controller, Figure.4a (iii) IMC controller with EFOC 
Performance Evaluation of DFIG During Asymmetrical Grid
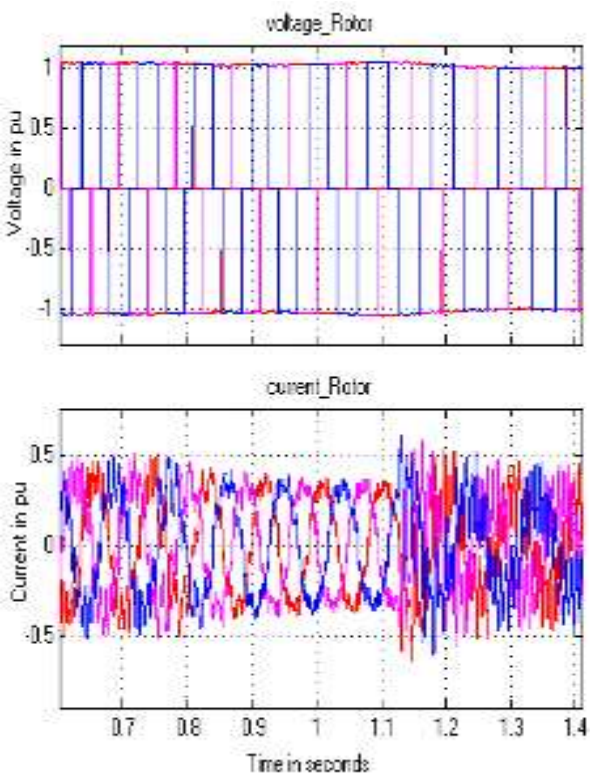

Figure $4 b(i)$
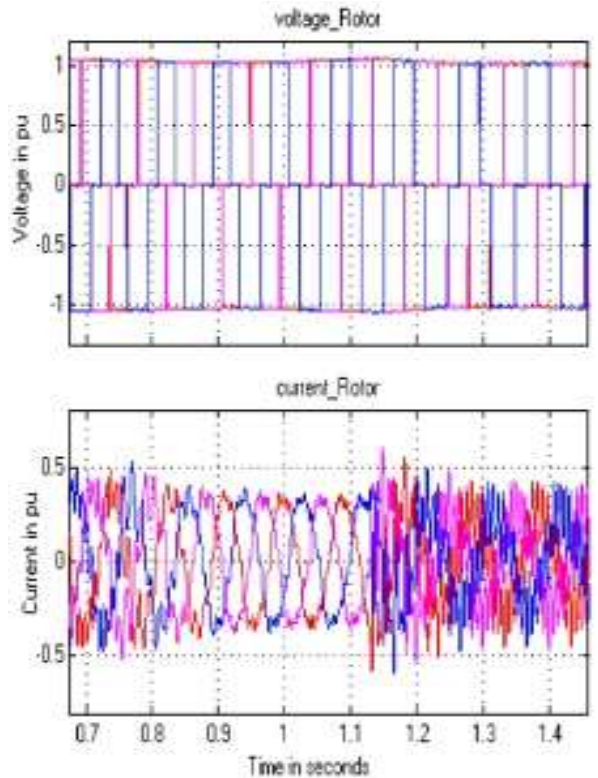

Figure $4 b$ (ii) 
D.V.N. Ananth, et al.
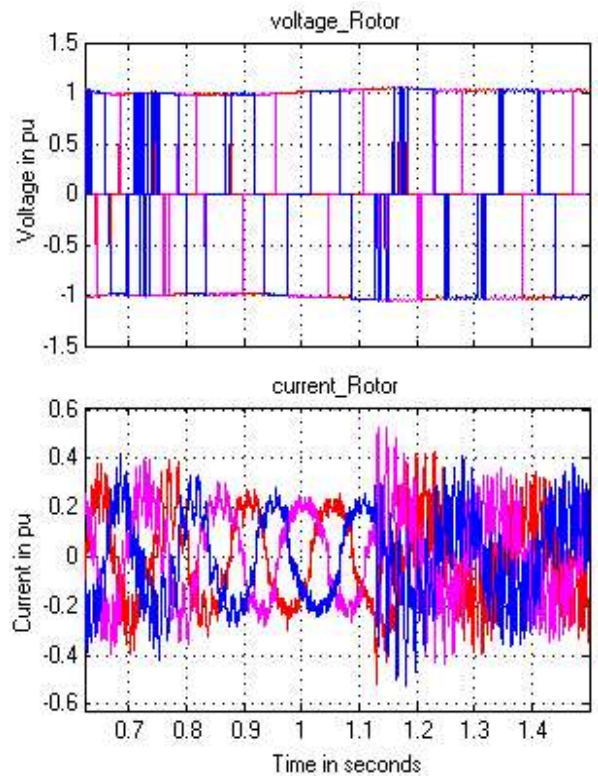

Figure $4 \mathrm{~b}$ (iii)

Figure $4 \mathrm{~b}$. Rotor voltage and current with (i) PI based controller, Figure.4b (ii) PIR controller, Figure.4b (iii) IMC controller with EFOC
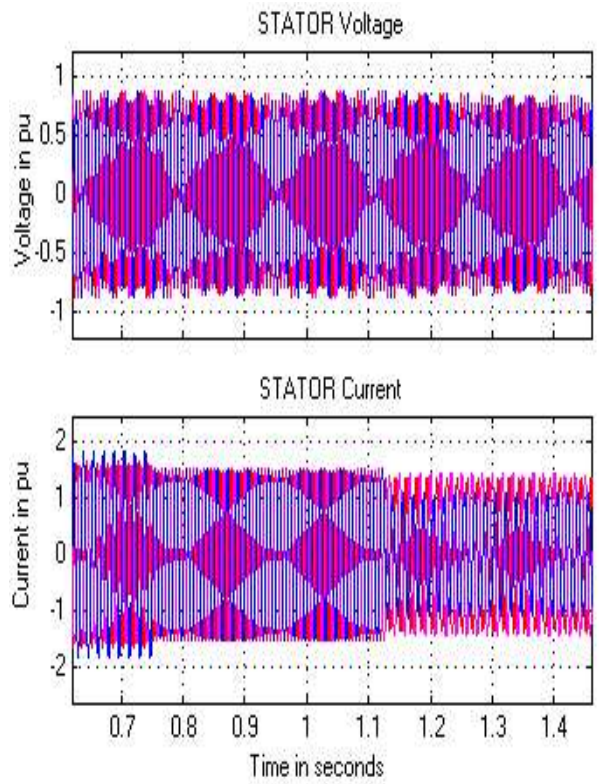

Figure. 4c (i) 

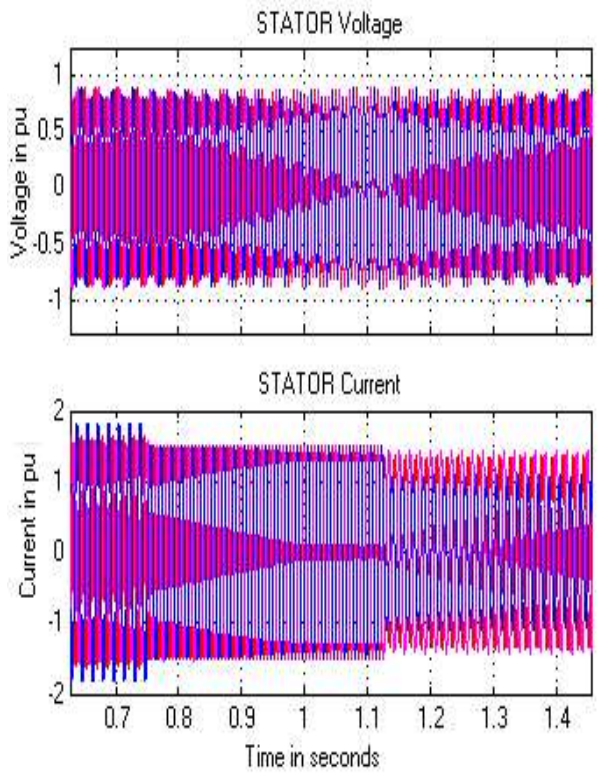

Figure. 4c (ii)

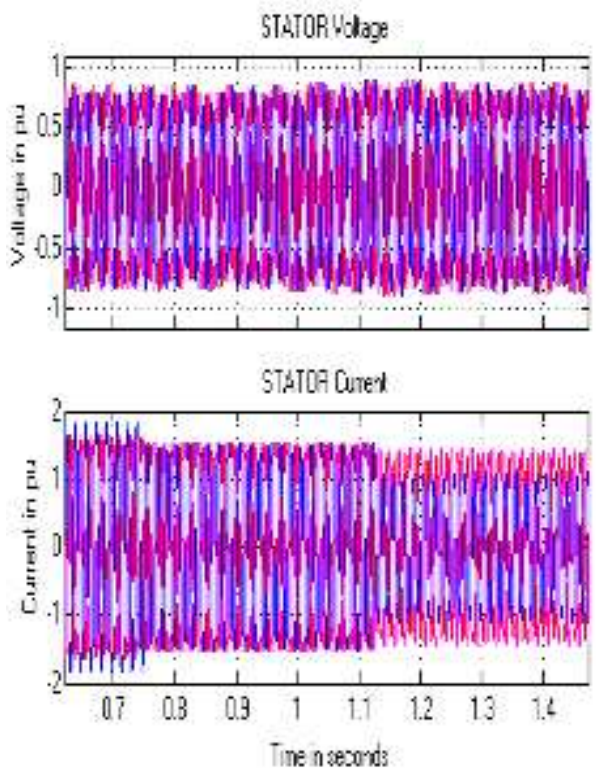

Figure. 4c (iii)

Figure 4c. stator voltage and current with (i) PI based controller, Figure.4c (ii) PIR controller, Figure.4c (iii) IMC controller with EFOC

The rotor phase voltages and currents with EFOC technique with PI, PIR and IMC are shown in figure $4 \mathrm{~b}$ (i), (ii) and (iii). With proposed EFOC technique with PI controller, performance of DFIG is better compared to conventional techniques proposed in the literature. There is voltage and current mitigation with magnitude almost constant, but with small distortions in the waveform during disturbances as shown in figure $4 \mathrm{~b}$ (i). During to swell, current is high and during sag current is low with much distortion in sine waveform. There is a small improvement in rotor current waveform as shown in figure 4 b(ii). Similarly, voltage and current waveforms in stator and rotor are also improved with IMC. Due to asymmetrical 
behavior and dynamic model designing of DFIG, the switching operation of faulted phase is controlled with IMC. In this phase-A is represented with blue color waveform. Hence with EFOC, the rotor winding voltage and current waveforms are improved. Further improvement can be achieved by placing PIR or IMC in internal control circuit of both RSC and GSC.

The stator winding voltage and current waveform using EFOC technique with PI controller is shown in Figure. 4c (i). Due to the non-linear and distorted and also grid phase-A is disturbing, small distortion in stator voltage is observed. The stator voltage and current behavior is nearly constant with all the three controllers in terms of maintaining constant voltage profile. However there is a small improvement in sine waveform for voltage can be observed with IMC in Figure 4c (iii) than with PIR in Figure 4c (ii). The performance with PI controller is inferior of the three.

The efficacy of converters performance on DFIG torque and speed and maintenance of nearly constant voltage across capacitor between RSC and GSC can be observed from Figure. 4d. With PI controller, the DC voltage across capacitor increased to $295 \mathrm{~V}$ during swell and reaches $285 \mathrm{~V}$ during normal operation. When sag in phase-A at the grid occurred, Dc voltage decreased to $278 \mathrm{~V}$ as shown in Figure. $4 \mathrm{~d}$ (i). The rotor speed also changed from 1.18pu rpm to $1.15 \mathrm{pu}$ rpm during grid disturbance. The EMT is at $-1 \mathrm{pu}$ up to $0.75 \mathrm{~s}$ during swell, reaches $0.8 \mathrm{pu}$ in normal situation till $1.15 \mathrm{~s}$ and with many oscillations and ripples during asymmetrical voltage sag. This EMT reaches zero and going to $+0.05 \mathrm{pu}$ at instant of voltage sag occurrence at $1.15 \mathrm{~s}$. This EMT surges and ripples are controlled by using PIR controller as shown in Figure. $4 \mathrm{~d}$ (ii). The torque never reached zero pu value during sag and also amplitude of torque ripples is decreased. The deviation from DC link voltage is only from $300 \mathrm{~V}$ to $278 \mathrm{~V}$. The rotor speed deviation is similar to the behavior with PI controller. There is a small voltage deviation in capacitor DC link voltage with IMC as shown in Figure.4d (iii). The variation in voltage is between 280 and 290V. During swell, Dc link voltage is at 280V, under normal situations it is $295 \mathrm{~V}$ and with sag in a phase voltage maintained to $290 \mathrm{~V}$. The rotor speed also maintained between 1.15 and $1.09 \mathrm{pu} \mathrm{rpm}$. There are few oscillations in torque waveform with IMC and ripples are minimized compared to PI and PIR.

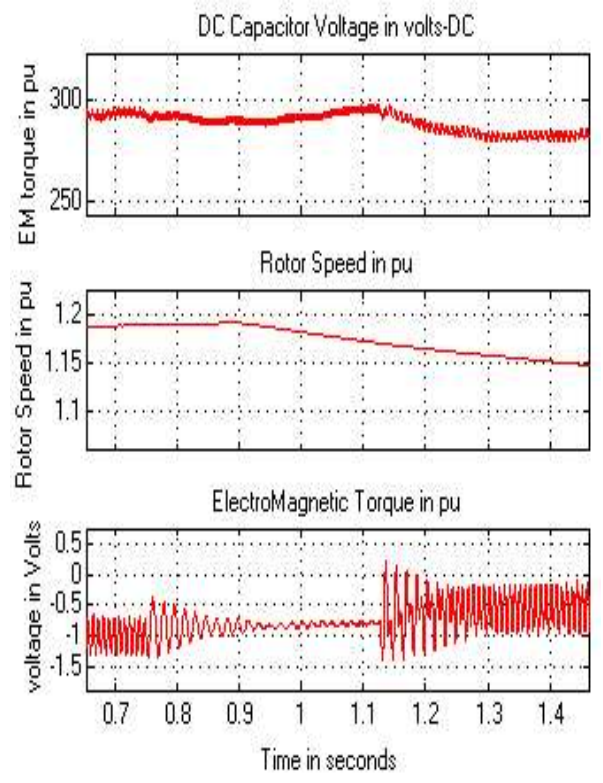

Figure. 4d (i) 

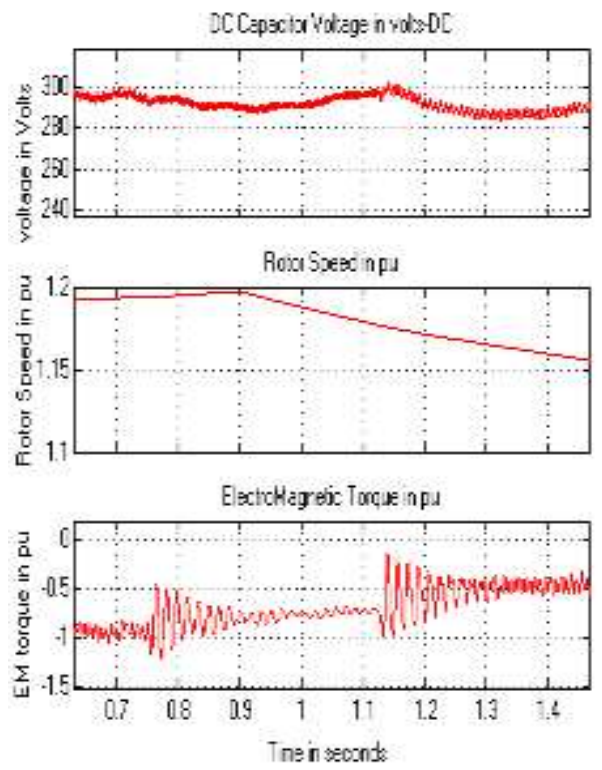

Figure. 4d (ii)
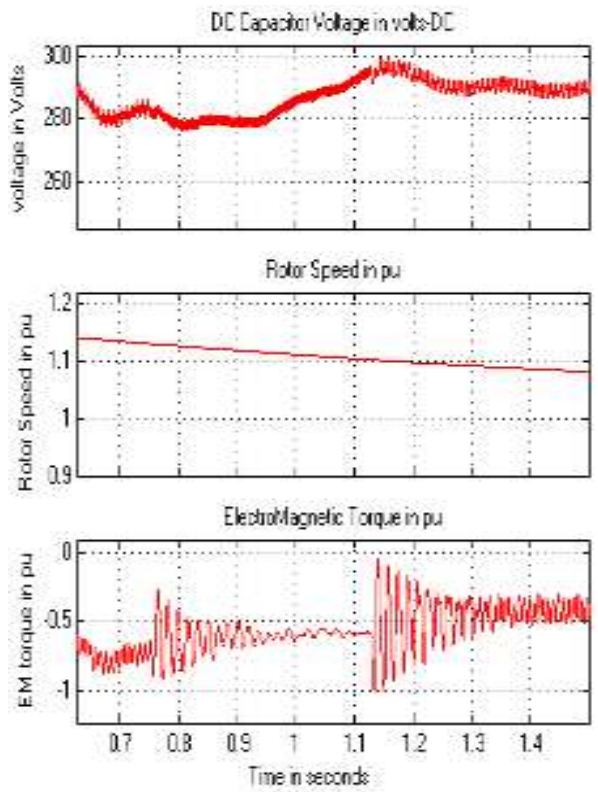

Figure. 4d (iii)

Figure 4d. DC capacitor voltage, generator speed and torque with (i) PI controller, (ii) PIR controller, (iii) IMC controller with EFOC 
Table 1. Summary of generator and grid parameters during grid sag and swell asymmetric disturbances

\begin{tabular}{|c|c|c|c|c|c|c|c|c|c|c|}
\hline \multirow[t]{2}{*}{$\begin{array}{c}\text { Parameters under } \\
\text { study }\end{array}$} & \multicolumn{3}{|c|}{$\begin{array}{c}\text { Phase A high voltage fault }(1.3 \mathrm{pu}) \\
\text { during } 0.6 \text { to } 0.75 \mathrm{~s} \text { (parameters in } \\
\text { phase } \mathrm{A} \text { alone, unless specified) }\end{array}$} & \multicolumn{3}{|c|}{$\begin{array}{l}\text { Normal voltage }(1 \mathrm{pu}) \\
\text { during }(0.75 \text { to } 1.15 \mathrm{~s})\end{array}$} & \multicolumn{3}{|c|}{$\begin{array}{l}\text { Phase A low voltage fault }(0.5 \mathrm{pu}) \\
\text { during } 1.15 \text { to } 1.4 \mathrm{~s} \text { (parameters in } \\
\text { phase A alone, unless specified) }\end{array}$} & \multirow[t]{2}{*}{ Remarks } \\
\hline & PI & PIR & IMC & PI & PIR & IMC & PI & PIR & IMC & \\
\hline Grid voltage (pu) & 1.3 & 1.3 & 1.3 & 1.0 & 1.0 & 1.0 & 0.5 & 0.5 & 0.5 & $\mathrm{~B}, \mathrm{C}$ phases $1.0 \mathrm{pu}$ \\
\hline Grid current $(\mathrm{pu})$ & 0.75 & 0.75 & 0.75 & 0.5 & 0.5 & 0.5 & 0.25 & 0.25 & 0.5 & \\
\hline Rotor voltage (pu) & 1.0 & 1.0 & 1.0 & 1.0 & 1.0 & 1.0 & 1.0 & 1.0 & 1.0 & All phases same \\
\hline Rotor current $(\mathrm{pu})$ & 0.5 & 0.5 & 0.4 & 0.3 & 0.3 & 0.25 & 0.52 & 0.51 & 0.5 & $\begin{array}{c}\text { IMC, PIR less } \\
\text { distortions during } \\
\text { fault }\end{array}$ \\
\hline Stator voltage $(\mathrm{pu})$ & 0.75 & 0.75 & 0.75 & 0.75 & 0.75 & 0.75 & 0.75 & 0.75 & 0.75 & All phases same \\
\hline $\begin{array}{l}\text { Stator current (pu) in } \\
\text { phase-A, other phases } \\
\text { constant }\end{array}$ & $\begin{array}{l}\text { A-1.75 } \\
\text { B,C-1.5 }\end{array}$ & 1.75 & 1.75 & $\begin{array}{l}1.5 \text { in } \\
\mathrm{A}, \mathrm{B}, \mathrm{C}\end{array}$ & 1.5 & 1.5 & $\begin{array}{l}\text { A-1.0 } \\
\text { B,C- } \\
1.5\end{array}$ & $\begin{array}{l}\text { A-1.25 } \\
\text { B,C-1.5 }\end{array}$ & $\begin{array}{l}\text { A-1.35 } \\
\text { B,C-1.5 }\end{array}$ & $\begin{array}{c}\text { IMC, PIR less } \\
\text { distortions during } \\
\text { fault in all phases }\end{array}$ \\
\hline $\begin{array}{c}\text { DC voltage across } \\
\text { capacitor (volts) }\end{array}$ & 285 & 290 & 280 & 270 & 285 & 280 & 265 & 283 & 290 & $\begin{array}{c}\text { Deviation is low } \\
\text { with IMC }\end{array}$ \\
\hline Rotor speed(pu) & 1.18 & 1.19 & 1.12 & 1.16 & 1.16 & 1.11 & 1.15 & 1.16 & 1.1 & $\begin{array}{c}\text { Speed remained } \\
\text { almost constant in } \\
\text { all cases, better is } \\
\text { with IMC }\end{array}$ \\
\hline $\begin{array}{l}\text { Electromagnetic } \\
\text { torque }(\mathrm{pu})\end{array}$ & -1.25 & -0.9 & $\begin{array}{l}-0.5 \text { with } \\
\text { oscillations }\end{array}$ & -1 & -0.9 & $\begin{array}{c}-0.5 \\
\text { low } \\
\text { oscilla } \\
\text { tions }\end{array}$ & -0.85 & -0.7 & $\begin{array}{l}-0.45 \text { limited } \\
\text { oscillations }\end{array}$ & $\begin{array}{l}\text { Torque oscillations } \\
\text { limited with PIR or } \\
\text { IMC techniques } \\
\text { than with PI. }\end{array}$ \\
\hline
\end{tabular}

\section{Discussion}

A conventional DFIGURE wind turbine system connected to the grid was considered in the analysis with proposed EFOC technique. The system is analyzed for voltage swell and sag type grid disturbance in phase A and the behavior of DFIG is studied with controllers like PI, PIR and IMC. The internal control loops of RSC and GSC with PI are replaced with PIR and IMC. Phase-A grid voltage swell to $30 \%$ occurred at $0.6 \mathrm{~s}$ and cleared at $0.75 \mathrm{~s}$. In the same phase, a sag of $50 \%$ occurred between 1.15 and $1.4 \mathrm{~s}$. Under these two disturbances, the generator winding parameters was studied and found that the rotor and stator currents during the fault is maintained near to its pre-fault value with proposed method. In conventional technique, the waveform will have DC components and harmonics with sub-transient and transient components. The grid voltage in phase-An increased and current in B and C 
phases increased. During sag, voltage in phase-A decreased and current in same phase increased. The stator and rotor winding voltages is nearly constant with EFOC technique, but small changes in current are observed. This performance is however much better than a conventional control techniques like sequence compensation etc. the torque pulsation are also reduced with proposed IMC.

The proposed EFOC technique helps in controlling the change in affecting in other nonfaulted phase compared to literature [6,10 and15]. The overall system stability can be improved using EFOC. The deviation from faulty phase is controlled and all parameters are within limits. The IMC and PIR controllers are having better performance than with PI controller. Among PIR and IMC, later is having best performance during asymmetric faults. Compared to normal conditions, the deviation from DC link voltage across capacitor varies with 15 volts with PI, 5 volts with PIR and 3 volts with IMC. The deviation from rotor speed is also lowest with IMC. Compared to PI, PIR is having lesser deviation from speed of the rotor. The torque oscillations and their damping are nearly same with PIR and IMC. The magnitude of torque produced for given wind speed, PIR is having more value than with IMC. When comparing proposed PIR based EFOC technique with PIR based technique in [16], due to symmetrical voltage dip, the torque value reached to a smaller value and has oscillations. The stator and rotor currents as well as the DC voltage across capacitor are having more harmonic content and waveform distortion in $[15,16]$ compared to proposed technique.

From the equations (7A-10), with the change in the stator and rotor flux linkage value and rotor slip, the rotor voltage increases slightly exponentially to certain value because of change in back emf of DFIGURE. Because of this, based on Figure.2, it can be observed that rotor current, thereby stator current will decrease with a proposed scheme instead of increasing during a fault. The oscillations are damped due to the fast acting IMC, hence is preferred over the PI controller. A conventional PI controller with rules available in the literature are used in the paper. The increase in torque initially is because of the decrease in electrical power and constant mechanical power. the unbalance between these two energies make the torque and speed to increase. It shows the performance improvement during and after a fault and has better working conditions than in available literature. There is a surge in torque at $0.1 \mathrm{~s}$ at fault occurring instant. Based on equation (13b), moment of inertia $\mathrm{J}$, mechanical torque does not vary, but the rotor speed varies. The rotor speed remained almost constant with this EFOC technique with IMC. This is another major advantage with the proposed system to maintain a constant speed of the rotor during a fault. To satisfy the equality constraint with change in rotor speed, EMT also varies. The variation in mechanical torque is low compared to electrical torque because electrical system operates faster than a mechanical system as explained by equal area criteria. Due to the inertia in the machine, rotor speed will increase during fault and decreases to normal once fault is cleared. The role of IMC helps in damping out oscillations during fault and to reach steady state quickly. This IMC also helps in controlling the flux decay desired by proposing an EFOC technique to stubborn control over $\mathrm{d}$ and $\mathrm{q}$ axis currents in RSC circuit.

The reactive power control adopted in RSC will control the change in reactive power. If this reactive power control is done in GSC, the reactive power compensation can be better. With the change in EMT, rotor speed and impedance at Point of Common Coupling (PCC), the real and reactive power flow from the generator to grid changes. A sag up to 0pu volts at fault instant $0.1 \mathrm{~s}$ in dc voltage dip is observed at fault instant, due to unexpected occurance of fault. With fast acting control strategy, the voltage dip can be mitigated. Even if the fault exists for more than $0.5 \mathrm{~s}$ time period, the system can sustain stability as dc capacitance voltage is maintained constant at back-to-back converters. The dc capacitor rating at back-to-back converters will also play a vital role in storing and delivering this excess current during the faults. The GSC circuit, helps in controlling the decay in DC link voltage, thereby overall stability is improved.

It is due to severity of fault which is occuring with a very low impedance value. To much decrease in grid voltage, inrush current entering into the stator and rotor winding will increase 
very rapidly and produces surges in current waveforms. If these surges are not limited, both the windings and the converterss will get damaged. For the protection of the rotor winding and further stator winding from severe inrush current surges, the crowbar is generally used. But with the proposed control circuit, this crowbar scheme can be eliminated. No need of external real or reactive power sources. However, limiting surges at fault instances are not completely eliminated and can be said to be future scope of the work. Compared to the work discussed previously in the literature, this method can have better sustainable operation and continuity of current flow with improved performance in all respects.

\section{Conclusion}

A better rotor current waveform is observed with PIR and IMC than PI controller. IMC performed better than PIR due to internal structure of plant (DFIGURE) model and observability technique adopted respectively. The generator torque is having few ripples at swell in phase and settled with oscillations once the fault is cleared. There are huge ripples in EMT with amplitude of 0.05 to $-1.5 \mathrm{pu}$ is observed with PI controller of $50 \%$ dip in the grid voltage of phase-A. This is a huge fault with DFIGURE as its converter rating is very low so as to sustain to such oscillations and to damp them effectively. Moreover, with EFOC the performance was improved. When PIR or IMC is used, the ripples in EMT during asymmetrical fault in phase-A was reduced effectively and minimized to nearly half with PI. The DC link voltage is also maintained nearly constant during the fault with all three controllers. The deviation in capacitor DC link voltage is further reduced with IMC or PIR controllers. Overall performance of DFIGURE during asymmetrical grid disturbance can be improved with proposed EFOC technique. To further extend the performance a PIR and proposed IMC can be used. For faults much lesser than $40 \%$ dip or rise, it is found that RSC and GSC controller circuits cannot provide effective compensation in generator voltage and current. The torque ripples and speed deviation can be controlled more efficiently with proposed EFOC with IMC or PIR. Performance with IMC is better than PIR than PI controllers. It is also found that synchronism still persist for fault occurring for more than $0.3 \mathrm{~s}$ with dip of 50\%. For conventional technique, EMT has high frequency oscillations with rotor speed uncontrollable during fault. Decay in stator and rotor flux is controlled when changing the reference synchronous speed value as described in Figure. 2 during fault. The above all are the major contributions with the proposed strategy.

\section{Appendix}

The parameters of DFIG used in simulation are:

Rated Power $=1.5 \mathrm{MW}$, Rated Voltage $=690 \mathrm{~V}$, Stator Resistance Rs $=0.0049 \mathrm{pu}$, rotor Resistance $\mathrm{Rr}=0.0049 \mathrm{pu}$, Stator Leakage Inductance Lls $=0.093 \mathrm{pu}$, Rotor Leakage inductance Llr1 $=0.1 \mathrm{pu}$, Inertia constant $=4.54 \mathrm{pu}$, Number of poles $=4$, Mutual Inductance $\mathrm{Lm}=3.39 \mathrm{pu}, \mathrm{DC}$ link Voltage $=1200 \mathrm{~V}, \mathrm{DC}$ link capacitance $=0.002 \mathrm{~F}$, Wind speed $=14$ $\mathrm{m} / \mathrm{sec}$. Grid Voltage $=25 \mathrm{KV}$, Grid frequency $=60 \mathrm{~Hz}$.Grid side Filter: Rfg $=0.3 \Omega, \mathrm{Lfg}=$ $0.6 \mathrm{nH}$, Rotor side filter: $\mathrm{Rfr}=0.3 \mathrm{~m} \Omega, \mathrm{Lfr}=0.6 \mathrm{nH}$,

\section{References}

[1]. Wang Yun ; Zhao Dong-li ; Zhao Bin ; Xu Hong-hua, "A Review of Research Status on LVRT Technology in Doubly-fed Wind Turbine Generator System”, Proc. on ICECE, 2010, pp: $4948-4953$.

[2]. Shuai Xiao ; Hua Geng ; Honglin Zhou ; Geng Yang, "Analysis of the control limit for rotor-side converter of doubly fed induction generator-based wind energy conversion system under various voltage dips", IET Renewable Power Generation, Volume: 7, 2013, pp: $71-81$

[3]. Shuai Xiao ; Geng Yang ; Honglin Zhou ; Hua Geng, “An LVRT Control Strategy Based on Flux Linkage Tracking for DFIGURE-Based WECS", IEEE Transactions on Industrial Electronics, Volume: 60 , Issue: 7, 2013 , Pp: 2820 - 2832 
[4]. Alejandro Rolán, Joaquín Pedra, Felipe Córcoles, "Detailed study of DFIGURE-based wind turbines to overcome the most severe grid faults", Electrical Powwe and Energy Systems. Volume. 62, no. 2, June 2014, pp.868-878.

[5]. Lihui Yang ; Zhao Xu ; Ostergaard, J. ; Zhao Yang Dong ; Kit Po Wong, "Advanced Control Strategy of DFIG Wind Turbines for Power System Fault Ride Through," IEEE Transactions on Power Systems, Volume: 27 , Issue: 2,2012 , Pp: 713 - 722

[6]. Mohsen Rahimi, Mostafa Parniani, "Low voltage ride-through capability improvement of DFIGURE-based wind turbines under unbalanced voltage dips", Electrical. Power and Energy System Volume. 60, no. 1, Mar 2014, pp.82-95.

[7]. Jiaqi Liang ; Howard, D.F. ; Restrepo, J.A. ; Harley, R.G., "Feedforward Transient Compensation Control for DFIG Wind Turbines During Both Balanced and Unbalanced Grid Disturbances" IEEE Transactions on Industry Applications, Volume: 49 , Issue: 3, 2013 , pp: $1452-1463$

[8]. Jiaqi Liang ; Wei Qiao ; Harley, R.G., "Feed-Forward Transient Current Control for LowVoltage Ride-Through Enhancement of DFIG Wind Turbines", IEEE Transactions on Energy Conversion, Volume: 25 , Issue: 3, 2010 , pp: 836 - 843

[9]. Wei Chen, Xiujie Geng, Tao Liu, Changliang Xia, "Stationary frame deadbeat power control of three-phase PWM rectifiers under unbalanced grid voltages", Elec. Power System Resarch Volume. 108, Mar 2014, pp.82-95.

[10]. Oriol Gomis-Bellmunt, Adria Junyent-Ferr 'e, Andreas Sumper ' , and Joan BergasJane', "Ride-Through Control of a Doubly Fed Induction Generator Under Unbalanced Voltage Sags", IEEE Transactions on Energy Conversion, Volume. 23, no. 4, Dec 2008, pp..1036-1045.

[11]. Jiabing $\mathrm{Hu}$, and Yikang He, "Reinforced Control and Operation of DFIGURE-Based Wind-Power-Generation System Under Unbalanced Grid Voltage Conditions", IEEE Transactions on Energy Conversion, Volume. 24, no. 4, Dec 2009, pp..905-915.

[12]. Xiangwu Yan, Giri Venkataramanan, Yang Wang, Qing Dong, and Bo Zhang, Grid-Fault Tolerant Operation of a DFIG Wind Turbine Generator Using a Passive Resistance Network", IEEE transactions on power electronics, Volume. 26, no. 10, Oct 2011, pp..2896-2905.

[13]. Andres E. Leon, Juan Manuel Mauricio, and Jorge A. Solsona," Fault Ride-Through Enhancement of DFIG-Based Wind Generation Considering Unbalanced and Distorted Conditions", Transactions on Energy Conversion, Volume. 27, no. 3, Sep 2012, pp..775783.

[14]. Ananth DVN and Nagesh Kumar GV., "Fault ride-through enhancement using an enhanced field oriented control technique for converters of grid connected DFIGURE and STATCOM for different types of faults", ISA Transactions (2015), http://dx.doi.org/10.1016/j.isatra.2015. 02.014i

[15]. Jean Patric da Costa, Humberto Pinheiro, Thomas Degner and Gunter Arnold, " Robust controller for DFIG of Grid-connected wind turbines", IEEE transactions on industrial electronics, Volume. 58, no. 9, Sept 2011, pp..40236-4038.

[16]. Jiabing Hu, Yikang He, "Modeling and enhance d control of DFIGURE under unbalance d grid voltage conditions", Electric Power Systems Research, Vol.79, pp.273-281, 2009.

[17]. Shen, Y. W., Ke, D. P., Sun, Y. Z., Kirschen, D. S., Qiao, W., \& Deng, X. T. “Advanced Auxiliary Control of an Energy Storage Device for Transient Voltage Support of a Doubly Fed Induction Generator", IEEE Trans. Sustainable Energy, DOI: 10.1109/TSTE.2015.2472299, 2015..

[18]. Huang, Qingjun, Donghai Zhu, and Yong Kang. "Scaled Current Tracking Control for Doubly Fed Induction Generator to Ride-through Serious Grid Faults.", IEEE Trans. Power Electron., DOI: 10.1109/TPEL.2015.2429153, 2015.

[19]. Zhu, Rongwu, Zhe Chen, Xiaojie Wu, and Feiqi Deng. "Virtual Damping Flux-Based LVRT Control for DFIGURE-Based Wind Turbine." IEEE Trans. Energy Convers., vol. 30, no. 2, pp. 714-725, Jan. 2015. 
[20]. Zhou, Liang, Jiangchuan Liu, and Shiyu Zhou. "Improved Demagnetization Control of a Doubly-fed Induction Generator under Balanced Grid Fault.", IEEE Trans. Power Electron., vol. 30, no. 12, pp. 6695 - 6705, Dec. 2014.

[21]. Guo, W., Xiao, L., Dai, S., Xu, X., Li, Y., \& Wang, Y. (2015). Evaluation of the Performance of BTFCLs for Enhancing LVRT Capability of DFIG, IEEE Trans. Power Electron vol.30, no.7, pp: 3623-3637, July 2014.

[22]. Xiao, Shuai, Geng Yang, and Hua Geng. "Analysis of the control limit of crowbar-less LVRT methods for DFIGURE-based wind power systems under asymmetrical voltage dips." Innovative Smart Grid Technologies Asia (ISGT), 2011 IEEE PES. IEEE, 2011.

[23]. Guo, Wenyong, Liye Xiao, Shaotao Dai, Yuanhe Li, Xi Xu, Weiwei Zhou, and Luo Li. "LVRT capability enhancement of DFIG with switch-type fault current limiter." . IEEE Trans. Inds. Electron, vol.62, no. 1, pp:332-342, May2014.

[24]. Shen, Y. W., Ke, D. P., Qiao, W., Sun, Y. Z., Kirschen, D. S., \& Wei, C. "Transient ReconFigureuration and Coordinated Control for Power Converters to Enhance the LVRT of a DFIG Wind Turbine With an Energy Storage Device", IEEE Trans. Power Electron., DOI: 10.1109/TEC.2015.2449900.

[25]. Q. Huang, X. Zou, D. Zhu and Y. Kang, "Scaled Current Tracking Control for Doubly Fed Induction Generator to Ride-Through Serious Grid Faults," in IEEE Transactions on Power Electronics, vol. 31, no. 3, pp. 2150-2165, March 2016.

[26]. R. Zhu, Z. Chen, Y. Tang, F. Deng and X. Wu, "Dual-Loop Control Strategy for DFIGURE-Based Wind Turbines Under Grid Voltage Disturbances," in IEEE Transactions on Power Electronics, vol. 31, no. 3, pp. 2239-2253, March 2016.

[27]. R. Zhu, Z. Chen, X. Wu and F. Deng, "Virtual Damping Flux-Based LVRT Control for DFIGURE-Based Wind Turbine," in IEEE Transactions on Energy Conversion, vol. 30, no. 2, pp. 714-725, June 2015.

[28]. V. F. Mendes, C. V. de Sousa, W. Hofmann and S. R. Silva, "Doubly-fed induction generator ride-through fault capability using resonant controllers for asymmetrical voltage sags," in IET Renewable Power Generation, vol. 9, no. 7, pp. 783-791, 92015.

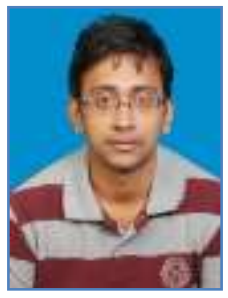

D.V.N. Ananth was born in Visakhapatnam, India. He received B.Tech Electrical Engineering from Raghu Engineering College, Visakhapatnam andM.Tech from Sreenidhi Institute of Science \& Technology, Hyderabad, India. He is working as an Assistant Professor in DADI Institute of Engineering and Technology in Electrical Department since August 2016. $\mathrm{He}$ is currently working towards his $\mathrm{PhD}$ degree from GITAM University, Visakhapatnam His favorite topics include Renewable energy resources, DFIG, industrial drives, power systems, power electronics, control systems, HVDC and Reactive power compensation techniques.

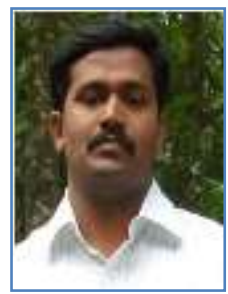

G.V. Nagesh Kumar was born in Visakhapatnam, India. He graduated College of Engineering, Gandhi Institute of Technology and Management, Visakhapatnam, India, Masters Degree from the College of Engineering, Andhra University and Visakhapatnam, India. He received his Doctoral degree from Jawaharlal Nehru Technological University, Hyderabad. He is presently working as Professor in the Department of Electrical and Electronics Engineering, GITAM University. His researches interests include gas insulated substations, fuzzy logic and neural network applications, distributed generation, Partial Discharge Studies and Bearing-less drives. He has published more than 175 research papers in national and international conferences and journals. He received "Sastra Award", "Best Paper Award" and "Best Researcher Award". He is a member of various societies, ISTE, IEEE, IE and System Society of India. He is also a reviewer for IEEE Transactions on Dielectrics and Electrical Insulation, Power Systems and a member on Board of several conferences and journals. 